\title{
Joji: A Play of Authoritarian Parenting
}

Sashi B Gupta ${ }^{1} \odot$, Niva Jacob² ${ }^{\infty}$, Mahesh R Gowda $^{3}$, Preeti Srinivasa ${ }^{4}$, Chandrashekar Muthyalappa ${ }^{5}$, Santhosh Madhukar Nambiar $^{6}$, Suganya Ponnaiah Pillai Krishna Pillai ${ }^{7}$

\begin{abstract}
Joji is a 2021 Indian Malayalam-language black crime drama film directed by Dileesh Pothan and written by Syam Pushkaran. Based on William Shakespeare's Macbeth, this movie is about an upper middle class Christian family in the high ranges of Kerala during the coronavirus disease 2019 pandemic. This movie portrays a father being authoritative leading to internalizing and externalizing behaviors like aggressiveness, defiance, poor-coping skills, self-harm, and submissiveness in his children.

Keywords: Authoritarian parenting, Joji, Movie.

Indian Journal of Private Psychiatry (2021): 10.5005/jp-journals-10067-0090
\end{abstract}

\section{INTRODUCTION}

The movie starts with Poppy (Alser Alex), who is a socially withdrawn unhappy grandson of Mr Kuttapan (authoritarian head of the Panachel family), ordering an air gun using Kuttappan's netbanking account without his knowledge. This act of delinquency is misdirected by Kuttappan (PN Sunny) towards Joji (Fahadh Fasil), his youngest son and the film's lead character, who assumes him to be the miscreant and a loser, in the form of harsh punishment. Kuttappan, a widower and the head of the Panachel family, is depicted as a strict patriarchal authoritarian father who expresses no warmth towards his family members, gives harsh punishments, and controls the finances and other important family decisions. His control over financial matters is illustrated when he physically abuses Joji over his investment in horse-trading and also does not permit Jaison (Joji Mundakkayam), his second son, to buy an apartment in the city.

Joji is unsuccessful in most of his ventures to earn easy money and is seen spending most of the days loitering around. He is financially dependent on his father and is restricted to express his emotions in the family as depicted by his silent anguish when alone in his room. He manipulates Poppy to reveal details of online transactions with an aim to steal money from Kuttappan's account for his aspirations.

Jaison, husband of Bincy (Unnimaya), is a hardworking family man, living by the societal norms, managing the family finances like a clerk for his father, but without any respect or recognition. His submissiveness and under-confidence cause struggles in the relationship between his father and his wife. He is anxious while discussing topics of his interest with his father, elder brother, or the priest. He finds it difficult to express his disagreement with significant others.

The patriarchal nature of the family is evident when Bincy is made to indulge in household chores like an unpaid maid.

The movie takes a turn when Kuttappan suffers from a stroke. Kuttappan's eldest son, Jomon (Baburaj), who is a divorcee and the father of Poppy, becomes the new head of the family after his father's serious condition. Being a single authoritarian parent along with his regular alcohol use would probably explain the distressed behavior of his son. Some of Kuttappan's family members see an opportunity for financial inheritance anticipating his death
${ }^{1-7}$ Department of Psychiatry, Spandana Nursing Home, Bengaluru, Karnataka, India

Corresponding Author: Sashi B Gupta, Department of Psychiatry, Spandana Nursing Home, Bengaluru, Karnataka, India, Phone: +91 7048979076, e-mail: shashi2007pmch@gmail.com

How to cite this article: Gupta SB, Jacob N, Gowda MR, et al. Joji: A Play of Authoritarian Parenting. Ind J Priv Psychiatry 2021;15(2):106-107.

Source of support: Nil

Conflict of interest: None

following serious health conditions and his recovery is seen as the loss of this opportunity. Joji secretly hatches a plan to murder him and succeeds with masked support from Bincy. Following their father's death, Jomon goes against social and religious norms when he decides to burst crackers at his funeral. He shows his authority by protecting the family from rumors circulating regarding their involvement in their father's death and also when he reminds the priest that the church is indebted to the Panachel family due to their generous donations.

Joji successfully murders Kuttappan but the subsequent chain of events to cover up the act ends in murdering his elder brother Jomon (Baburaj) as well. When Jaison, who is suspicious of Joji's heinous act and refuses to fall for his manipulations, Joji attempts suicide blaming society for his decisions. Many of the behavioral problems portrayed by Joji, including defiance, impulsivity, disruptiveness, aggression, antisociality, and self-harm is related to psychosocial factors of his dysfunctional family.

\section{Discussion}

Authoritarian parents are characteristically strict, punitive, controlling, and usually express less warmth. ${ }^{1}$ Such parents are very demanding and aim to exert control over a child's behavior. ${ }^{2}$ Authoritarian parenting is linked to externalizing and internalizing behavior, poor academic achievement, and poor self-concept. Externalizing behavior includes aggression, delinquency, and hyperactivity whereas internalizing behavior includes social withdrawal, anxiousness, and suicidal behavior. Children reared in such families are less independent, have poor self-control, and have

(c) The Author(s). 2021 Open Access This article is distributed under the terms of the Creative Commons Attribution 4.0 International License (https://creativecommons. org/licenses/by-nc/4.0/), which permits unrestricted use, distribution, and non-commercial reproduction in any medium, provided you give appropriate credit to the original author(s) and the source, provide a link to the Creative Commons license, and indicate if changes were made. The Creative Commons Public Domain Dedication waiver (http://creativecommons.org/publicdomain/zero/1.0/) applies to the data made available in this article, unless otherwise stated. 
difficulty in handling stressors. ${ }^{1}$ Jaison and Poppy are portrayed as submissive, socially unadept, under-confident, and less committed to achievement ${ }^{3}$ pointing towards internalizing behavior whereas externalizing behavior is present in varying degrees in characters of Jomon and Joji.

Identifying dysfunctional parenting styles and psychoeducation may prevent the risk of developing social, emotional, and behavioral problems in adolescence ${ }^{4}$ which may lead to self-harm. Parents need to consider the adolescents' age and adjust their parenting accordingly because late adolescents, perceive parental control as invasive and not as a sign of support, 5,6 and hence adolescence is the most challenging stage of childrearing. ${ }^{7}$ Hierarchical relationship in the family needs transformation to a more egalitarian type of relationship as the adolescent age progresses. ${ }^{8}$

\section{Conclusion}

Social, emotional, and behavioral problems in adolescents have long-lasting adverse consequences like self-harm and also impact families and society as a whole. It can be associated with several factors. One of the critical domains is the family environment which includes parenting style and communication pattern. This movie depicts how Kuttappan's authoritarian parenting style could have impacted the lives of Jomon, Jaison, and Joji differently.

\section{OrCID}

Sashi B Gupta ำ https://orcid.org/0000-0002-4409-8164

Niva Jacob (10 https://orcid.org/0000-0003-3805-8796

Preeti Srinivasa ㅇ https://orcid.org/0000-0001-9911-7927
Santhosh Madhukar Nambiar @ i https://orcid.org/0000-0001-71904988

Suganya Ponnaiah Pillai Krishna Pillai @ https://orcid.org/0000-00031960-4579

\section{References}

1. Sanavi FS, Baghbanian A, Shovey MF, et al. A study on family communication pattern and parenting styles with quality of life in adolescent. J Pak Med Assoc 2013;63(11):1393-1398. PMID: 24392526.

2. Calders F, Bijttebier P, Bosmans $G$, et al. Investigating the interplay between parenting dimensions and styles, and the association with adolescent outcomes. Eur Child Adolesc Psychiatry 2020;29(3): 327-342. DOI: 10.1007/s00787-019-01349-x.

3. Pinquart M. Associations of parenting dimensions and styles with externalizing problems of children and adolescents: an updated meta-analysis. Dev Psychol 2017;53(5):873. DOI: 10.1037/ dev0000295.

4. Lee SM, Daniels MH, Kissinger DB. Parental influences on adolescent adjustment: parenting styles versus parenting practices. Fam J 2006;14(3):253-259. DOI: 10.1177/1066480706287654.

5. Branje S. Development of parent-adolescent relationships: conflict interactions as a mechanism of change. Child Dev Perspect 2018;12(3):171-176. DOI: 10.1111/cdep.12278.

6. Sorkhabi N. Sources of parent-adolescent conflict:content and form of parenting. Soc Behav Personal 2010;38(6):761-782. DOI: 10.2224/ sbp.2010.38.6.761.

7. Buchanan CM, Eccles JS, Flanagan C, et al. Parents' and teachers' beliefs about adolescents: effects of sex and experience. J Youth Adolesc 1990;19(4):363-394. DOI: 10.1007/BF01537078.

8. Youniss J, Smollar JM. Adolescents' relations with mothers, fathers, and friends. Chicago: University of Chicago Press; 1985. 